\title{
Assistência social em risco: conservadorismo e luta social por direitos
}

\author{
Brazilian Social Assistance at risk: \\ conservateurism and social struggle for rights
}

\begin{abstract}
Jucimeri Isolda Silveira
Doutora em Serviço Social, mestra em Sociologia, professora do Curso de Serviço Social e do Programa de Pós-Graduação em Direitos Humanos e Políticas Públicas da PUC-PR, coordenadora da Área Estratégica e do Núcleo de Direitos Humanos. Curitiba-PR, Brasil.
\end{abstract}

jucimeri.silveira@pucpr.br

Resumo: Este artigo aborda as tendências regressivas na política de assistência social no Brasil, a partir da análise dos constrangimentos institucionais típicos do pacto federativo e das evidências de retrocessos que colocam em risco as bases do Sistema Único de Assistência Social, com flagrante aprofundamento da programática neoliberal, numa conjunta de avanço das contrarreformas, ameaça à democracia e de redução dos direitos. A partir da análise das evidências de retrocessos, reafirma-se o necessário fortalecimento das formas de resistência e lutas sociais pela dignidade humana.

Palavras-chave: Assistência Social. Conservadorismo. Gerencialismo. Direitos.

\begin{abstract}
This article deals with regressive trends in social assistance policy in Brazil, based on the institutional constraints typical of the federative pact and the evidence of setbacks that put the foundations of the Unified Social Assistance System at risk, with a flagrant deepening of the neoliberal program, A joint advance of counter-reforms, a threat to democracy and a reduction of rights. From the analysis of the evidence of setbacks, the necessary strengthening of forms of resistance and social struggles for human dignity is reaffirmed.
\end{abstract}

Keywords: Social Assistance. Conservatism, Managerialism. Rights.

\section{Introdução}

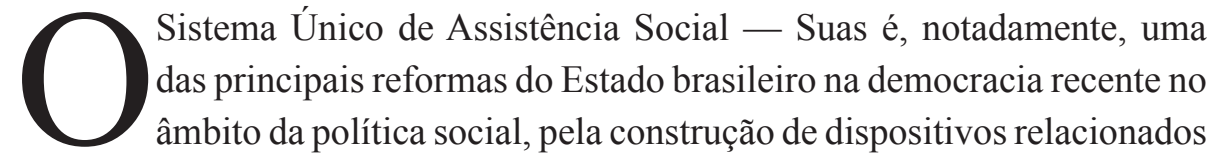
à concepção de uma política pública estatal, particularmente, pela provisão de 
seguranças tipificadas e padronizadas em equipamentos públicos estatais e referenciados nos territórios mais desiguais; lógica de repasses continuados e permanentes de recursos, fundo a fundo, a partir de critérios técnicos, orientados por princípios como a plena universalização, integralidade da proteção, com expansões qualificadas e progressivas; territorialização de serviços, visando à universalização de acessos; profissionalização, com definição de bases normativas que visam a desprecarização das condições e dos vínculos de trabalho, bem como qualidade dos serviços prestados; mecanismos indutores de capacidades de gestão, com definição de parâmetros de avaliação e ordenamento dos municípios e estados por níveis de gestão; implantação de novos instrumentos de gestão, especialmente o Pacto de Aprimoramento do Suas, tendo como finalidade a cooperação dos entes federados no cofinanciamento, na qualificação e na universalização da cobertura territorial, e no desenvolvimento normativo-jurídico e institucional; primazia da responsabilidade estatal e regulação de novas bases para a relação do Estado com as organizações da sociedade civil, entre outros aspectos que caracterizam a institucionalidade desse sistema público, descentralizado, participativo, destinado à gestão do conteúdo específico da assistência social no sistema protetivo brasileiro.

A despeito das divergências teóricas e políticas, especialmente no campo do Serviço Social, o Suas é reconhecido como um modelo estatal, público e democrático. Entretanto, o cenário atual revela tendências regressivas, ora explícitas, ora ocultadas pelas narrativas que se utilizam das fragilidades ainda presentes no sistema, como a dificuldade na execução de recursos repassados pelo Fundo Nacional de Assistência Social aos municípios e a ausência de padrões relativos aos custos dos serviços. Tais dificuldades compõem as justificativas adotadas pelo governo para a cristalização da agenda no Suas, especialmente na expansão do financiamento e dos serviços, inclusive os tipificados, mas não cofinanciados. É no contexto de contrarreformas neoliberais que o Programa Criança Feliz ganha centralidade, podendo se sobrepor, como programa de governo, ao próprio sistema estatal, embora os programas na assistência social sejam complementares a serviços e benefícios. Essa sobreposição se revela na hegemonização de uma concepção tecnicista de gestão pública, centrada nos resultados e na lógica da extrema focalização, num conjunto de avanços de medidas neoliberais. 
As análises críticas desse processo de desmonte, considerando o estágio de desenvolvimento do Suas e a conjuntura, tem como referência as pactuações e deliberações nas instâncias da política, as bases normativo-jurídicas, os instrumentos de gestão que induzem à implementação do Suas e a leitura da dinâmica das relações de força e poder em presença, polarizadas por projetos políticos em disputa. Deste modo, as fragilidades típicas do pacto federativo brasileiro dificultam as possibilidades de resistência por dentro do sistema, o que reforça a importância e a força dos movimentos e das formas de resistência, engendrada nas lutas mais gerais da classe trabalhadora, pela manutenção e expansão dos direitos, em defesa da democracia.

\section{Desigualdade e políticas públicas no Brasil: o problema do conservadorismo e do gerencialismo}

A crítica sobre a trajetória histórica das políticas públicas no Brasil, especialmente as sociais, tendo como parâmetro os princípios da universalidade do Sistema de Proteção Social e da indivisibilidade dos direitos humanos, parte da identificação de políticas inconsistentes, produzidas em períodos de autoritarismo e de ideologias desenvolvimentistas, conformando a incompletude da cidadania e da democracia. As políticas sociais revelam, historicamente, a prevalência do controle dos pobres e da moralização da pobreza; ajustamento dos improdutivos e incapacitados a um padrão normativo dominante; ineficiência, frágil alcance social, com sobreposição de competências e processos de descontinuidades; absoluta fragmentação e separação programática entre as políticas; destinação insuficiente de recursos públicos.

A configuração do padrão de proteção social brasileiro, erguido na era dos monopólios, caracteriza-se pela fragmentação, seletividade e focalismo em resposta às múltiplas expressões da questão social, justificada política e teoricamente por perspectivas conservadoras, expressas, especialmente, na defesa de instituições como a família tradicional; na valorização das hierarquias sociais; na naturalização da desigualdade e das assimetrias nas relações de poder; e no controle das insurgências produzidas na contradição de classes, pela criminalização dos movimentos sociais e organizações de defesa dos direitos. 
O aprofundamento da questão social e a intensa precarização das condições de vida são consequências do momento econômico, político e institucional, num cenário de globalização, com a intensificação das desigualdades interna e externa entre as nações. Em relação aos chamados países em desenvolvimento, explica Wacquant (2001), o agravamento da questão social coincide mais intensamente com a ampliação da violência, com as consequentes produção e difusão de discursos e práticas institucionais de extermínio, criminalização e encarceramento em massa da população pobre e negra. No caso brasileiro, a ampliação da desigualdade social se dá num momento de maior fragilização dos mecanismos democráticos de participação e controle social, com evidente desmonte de sistemas estatais público e de políticas de proteção aos direitos humanos, contribuindo para a reprodução de territórios desiguais e violadores de direitos.

A conjugação perversa entre cultura patrimonialista, reprodutora de assimetrias nas relações de poder sob os efeitos da ideologia do mando e do favor, e cultura gerencialista, incorporada na formulação das políticas públicas, a partir da racionalidade instrumental do mercado, configura uma feição de Estado com as seguintes dimensões: a) na dimensão social penalizadora da população em situação de pobreza e toda forma de insurgência que represente ameaça à dominação institucionalizada; b) na dimensão econômica gerencialista dos interesses do capital. É no contexto desse Estado que o processo de formulação de políticas públicas revela fragilidades, especialmente na implementação da descentralização de políticas públicas, distanciada de espacialização do poder, dada a configuração predominante de espaços de participação com capacidade limitada de incidência no processo decisório, notadamente pelos constrangimentos da burocratização das instâncias de participação; a baixa capacidade de gestão democrática deliberativa e qualificada das políticas públicas; o baixo grau de participação da sociedade civil do tipo estatal (Nogueira, 2003), ou seja, com efeitos de hegemonização de projetos emancipatórios, e não simplesmente integradores de programas de governo.

Sob a ideologia desenvolvimentista e a cultura patrimonialista disseminam-se concepções e práticas em gestão pública sustentadas no entendimento dos direitos como outorga, ou meramente inscritos nas legislações e demais ordenamentos jurídico-normativos, reforçando uma compreensão abstrata dos direitos, ao mesmo tempo em que legitima a posição de maior poder dos agentes 
públicos e governantes. Não é incomum o uso de táticas que justificam focalizações em programas e descontinuidades em serviços sociais, em detrimento de políticas estatais, portanto submetidas ao interesse republicano no acesso ao fundo público com controle democrático.

A política de assistência social possui um histórico de funcionalidade à reprodução da desigualdade, associando-se aos mecanismos e dispositivos de controle dos indivíduos e famílias; de criminalização dos pobres e ajustamento social no conjunto das oportunidades de integração aos programas sociais; de controle dos considerados desajustados à racionalidade instituída, com efeitos de subalternização, institucionalização, patologização e segregação social, contribuindo, desse modo, para o conformismo social.

Os projetos políticos na esfera pública do Estado também incidem na arquitetura institucional e na formulação da política de assistência social. Observa-se que na década de 1990 essa política permanece submetida à programática neoliberal e paralela aos programas de governo, com destaque ao Comunidade Solidária, lócus de legitimação da primazia do terceiro setor. É nesse contexto que a assistência social praticamente mantém as mesmas bases anteriores às diretrizes constitucionais e às previsões da Lei Orgânica de Assistência Social — Loas (Lei n. 8.742/93, alterada pela Lei n. 12.435/11). Por sua vez, as instâncias, em fase de institucionalidade, se ocupam de induzir uma descentralização burocrática, com insuficiente pactuação e cooperação interfederativa, ainda que algumas experiências locais/regionais de gestão e de organização política existissem e se revelassem potência democratizante no processo posterior de implantação do Suas.

\section{Constrangimentos da descentralização, participação e luta por direitos}

As políticas públicas implementadas pós-Constituição Federal de 1988 contribuíram para o desenvolvimento humano, especialmente as políticas de educação, saúde e assistência social, em cumprimento aos objetivos constitucionais, com destaque para a redução da pobreza e a estruturação de sistemas e políticas de proteção aos direitos humanos. Entretanto, é importante considerar a incompletude da cidadania para os parâmetros do que se compreende 
por desigualdade, conformando uma separação entre os direitos relacionados à liberdade e os direitos vinculados à igualdade, o que ganha contornos de maior residualidade e insuficiência pelo atraso histórico em políticas orientadas pelo princípio da universalidade do acesso.

As políticas públicas de proteção social são orientadas por princípios e diretrizes que demandam o necessário fortalecimento de mecanismos e processos democráticos, construídos a partir da cooperação entre os entes federados, com avanços legislativos e regulatórios que qualifiquem condições institucionais e políticas para a garantia da efetivação dos direitos. Nesse aspecto, a descentralização com efetiva territorialização de políticas e ações deve representar a efetiva partilha de poder entre o Estado e as coletividades locais.

É preciso considerar os processos que incidem no redesenho político, jurídico e administrativo do novo pacto federativo que orienta o padrão de proteção social brasileiro. As políticas setoriais e as transversais, ou de defesa de direitos, possuem especificidades quanto ao grau de descentralização e o nível de delimitação das atribuições das instâncias que compõem o sistema de gestão, fundamentalmente quanto às responsabilidades das esferas de governo. Todavia, persistem desafios da descentralização com participação efetivamente deliberativa, que supere a lógica de vinculação e subordinação dos municípios aos demais entes federados, assim como da sociedade civil em relação aos governos, no sentido da efetiva democratização deliberativa da política, na contramão da cultura gerencialista.

É consenso que a descentralização com atuação intersetorial territorial é indispensável, diante das dimensões continentais do país e das complexidades das cidades. A questão é superar modelos de gestão que pouco ou nada incidem nas decisões transformadoras dos territórios, além de reproduzirem a cultura política, pautada na ideologia do mando e do favor, expressão concreta da colonialidade do poder, aliada à cultura produtivista, burocrática e gerencialista, fundamentada na ideologia neoliberal. Todavia, não se trata apenas de um aprimoramento em modelos de gestão, mas de sistemas nacionais deliberativos afiançadores de direitos, com potência na reversão da desigualdade, o que certamente depende de projetos democráticos e emancipatórios.

O estudo e a compreensão das políticas públicas como um campo aberto e em disputa, para além de enfoques teóricos que se limitam a explicá-las em 
termos puramente institucionais e organizacionais, são análogos à compreensão dos direitos humanos na teoria crítica: produto cultural submetido a processos históricos, a construções abertas e sujeitas a transformações e dinâmicas sociais e políticas; conquistas parciais "arrancadas" na esfera pública do capital a partir da construção de condições políticas e institucionais; resultado das lutas sociais pela dignidade; expressão de interesses e relações de força e poder, tanto nas narrativas como nas legislações (Lima e Silveira, 2016). O caráter contraditório e heterogêneo do Estado, dos direitos e das políticas públicas desacomoda grupos sociais e coletivos inscritos nas instâncias de participação. Cabe o alerta aos efeitos ilusórios das perspectivas normativistas, abstratas e universalistas. Desse modo, as conquistas em termos de legislações, normas, políticas são fundamentais nos marcos das democracias, mas insuficientes. Quanto mais a participação estiver próxima da democracia deliberativa e autônoma, por isso distante da democracia meramente representativa, sustentada por certo elitismo burocrático, mais capacidade emancipatória anuncia, mais possibilidade transformadora pode acumular.

A análise crítica sobre a materialização dos direitos permite inferir que existe uma naturalização do distanciamento entre as prescrições e garantias legais e a realidade concreta no acesso aos direitos. Processo político e cultural agudizado pela realidade latino-americana quanto à formação social, com profunda desigualdade, marcada pelas pegadas coloniais "contidas nos planos normativos e culturais dos direitos humanos" (Carballido, 2014, p. 46), e inserção desigual e explorada no capitalismo mundial.

O processo de materialização dos direitos na contemporaneidade funda-se na compreensão da imprescindível superação das amarras dos limites institucionais na formulação de políticas e no acesso aos direitos, o que supõe o reconhecimento da condição substancial da cidadania na luta pela dignidade humana (Flores, 2009), engendrada nos processos sociais e políticos de organização e resistência. Além da centralidade das lutas sociais, outros pressupostos caracterizam uma compreensão crítica dos direitos humanos: o reconhecimento da produção de subjetividades como processo aberto de afirmação das diferenças, das singularidades; a defesa da relação indissociável entre os direitos de liberdade e os direitos de igualdade; a análise da necessária construção de bases materiais na conquista de direitos humanos para além da defesa de Estado social, 
caraterizado pelo fordismo desenvolvimentista e pelo capitalismo contemporâneo, diante do paradigma da flexibilização (produção, consumo e direitos), a partir do neoliberalismo. Portanto, coloca-se como horizonte a emancipação humana e como necessária a emancipação política nas lutas pela dignidade humana. Nesse sentido, os direitos não se confundem com as declarações, as normas, os planos e os acordos. Mas se materializam nas lutas concretas e cotidianas (individuais e coletivas), no processo de recriação da vida, das sociedades, de uma nova cultura construída a partir das experiências de humanização, dando, desse modo, sentido material às lutas e à vida.

A assistência social como política de Seguridade Social, orientada por princípios como a integralidade da proteção e a indivisibilidade dos direitos humanos, corre riscos caso permaneça aprisionada a uma institucionalidade endógena e direcionada por uma programática neoliberal em ascensão. A criação de instâncias, a elevada produção de normativas, a nacionalização do direito à assistência social foram processos fundamentais na construção de um novo modelo de gestão do conteúdo específico dessa política na proteção social brasileira. Entretanto, os processos de desmonte e redução de direitos podem ser ocultados pela racionalidade gerencialista por dentro do Suas. Cabe a reflexão: deliberar nas instâncias próprias do Suas tem sido suficiente para barrar a redução de recursos e as alterações no Benefício de Prestação Continuada, como a proposta de desvinculação do salário mínimo? O cenário de fragiliza-

ção do Suas - congelamento de recursos, conservadorismo, gerencialismo e focalismos - é dinamizado, de forma aberta ou disfarçada, pelo avanço de medidas neoliberais com flexibilização e redução dos direitos e desmonte de sistemas estatais públicos. Realidade que sinaliza como desafio fundamental a luta dos sujeitos políticos do Suas incorporada e presente nas lutas mais gerais em defesa dos direitos.

\section{Suas: diretivas, estágios e ameaças}

Com o advento da Constituição Federal de 1988 e a promulgação da Loas, a assistência social é definida como política pública, direito do cidadão e dever do Estado. Tal constitucionalização posiciona que o direito à assistência social deve ser assegurado a quem dela necessitar, orientando-se pelo princípio da 
universalidade no acesso, independentemente de contribuição prévia, por um conjunto integrado de ações de iniciativa pública e da sociedade, com primazia do Estado, demandando, desse modo, a estruturação de um sistema público estatal. ${ }^{1}$

O Suas representa um projeto de implantação de uma rede de proteção estatal, continuada, que contraria a programática neoliberal. As normativas produzidas e os processos construídos nas instâncias de negociação e deliberação são orientados por uma perspectiva alinhada aos propósitos de um sistema estatal, com algumas características centrais: definição e detalhamento de responsabilidades cooperadas entre entes; implantação de equipamentos estatais públicos; repasse de recursos continuados, com transações fundo a fundo, e fortalecimento dos espaços de controle democrático; mecanismos de publicidade e transparência no uso dos recursos e nos instrumentos de planejamento técnico; fomento à criação de fóruns populares (trabalhadores e usuários); mecanismos que induzem a concursos públicos e desprecarização das condições de trabalho; ativação das instâncias para unidade federativa, considerando, na atual fase do Suas, a diversidade e realidades locais; dispositivos e ferramentas de planejamento, monitoramento e avaliação de desenvolvimento institucional; produção legislativa para a qualificação do Suas.

O Suas foi a principal deliberação da Conferência Nacional de Assistência Social realizada em 2003, a partir da avaliação coletiva da insuficiência dos mecanismos utilizados até então, quanto às possibilidades de nacionalização do direito à assistência social, tendo em vista a necessária unificação de instrumentos de gestão e provisões, considerando as diversidades e desigualdades regionais e territoriais. Duas fases podem ser identificadas nesse processo: construção das bases do Suas de 2004 a 2012; aprimoramento do Suas de 2012 a 2015, culminando na aprovação do II Plano Decenal, construído a partir da X Conferência Nacional de Assistência Social (2015).

1. A assistência social teve seu avanço normativo associado ao reconhecimento dos direitos socioassistenciais no ordenamento jurídico brasileiro, com subsequente complementações regulatórias, compondo o chamado marco normativo-jurídico do Suas: $\mathrm{CF} / 88$, que insere a política de assistência social no tripé da seguridade social; PNAS/04 que detalha as atribuições, princípios e diretrizes da referida política; NOB-Suas/05 reformulada em 2012, que estabelece a estruturação do Suas; NOB-RH/Suas/06, que delimita a profissionalização e a qualificação das ofertas; Tipificação Nacional dos Serviços Socioassistenciais, que padroniza as prestações em âmbito nacional, entre outros. 
A Política Nacional de Assistência Social (Pnas/04) reafirma o caráter protetivo da assistência social, conforme previsão constitucional, e preconiza o fortalecimento de vínculos como um dos objetivos na prestação de serviços, considerando processos que vulnerabilizam indivíduos e famílias, e que podem ensejar violações de direitos, caracterizadas na Pnas como situações de risco pessoal e social. ${ }^{2}$

O objetivo, neste artigo, não é analisar as questões e polêmicas teóricas sobre a Pnas/04, mas identificar as particularidades do "modelo" de gestão, suas tendências e ameaças mais recentes. É importante sublinhar que é no momento de definição do conteúdo específico da assistência social na proteção social brasileira, por meio da Pnas/04, que o Suas comparece como sistema público de gestão a ser implementado para a garantia das seguranças relacionadas à função de proteção, assim como a implantação das demais funções, ou seja, a vigilância socioassistencial e a defesa de direitos.

Coube à Norma Operacional Básica do Sistema Único de Assistência Social (NOB/Suas/05) a regulação e organização do sistema público estatal, visando sua unificação e integração em todo o território nacional. Além de reafirmar as seguranças afiançadas, este instrumento normativo se ocupa em posicionar a responsabilidade estatal, com a definição dos tipos de gestão e dos níveis de habilitação, inaugurando, a exemplo da saúde, uma lógica de correspondência entre requisitos e incentivos, o que dinamiza as instâncias políticas do Suas. Nessa Norma não são "solucionados" os problemas típicos do pacto federativo no Suas. Ainda que existam responsabilidades bem demarcadas na Loas, como o cofinanciamento dos estados para benefícios eventuais, os entes federados se posicionam politicamente numa evidente verticalização: municípios com responsabilidades de ofertas de serviços; estados com função principal de monitorar e, para muitos, fiscalizar municípios; união com a coordenação nacional e repasse de recursos. Essa fase, portanto, foi estruturante e possibilitou que a assistência social se apresentasse como política pública na agenda dos governos e da própria sociedade civil, pela ampla difusão do sistema estatal e suas regras republicanas.

2. A proteção social não contributiva da política de assistência social é garantida por meio da prestação de serviços, programas, projetos e benefícios socioassistenciais, previstos na Loas, com o propósito de responder às necessidades básicas e garantir as seguranças de renda, convivência familiar e comunitária e de provisão de acolhimento em situações específicas de risco pessoal e social (Pnas/04). 
Apesar das limitações em termos da indução de responsabilidades cooperadas, a primeira fase do Suas é marcada por uma expansão e territorialização de serviços estatais, relativamente patronizados por meio da Tipificação Nacional de Serviços Socioassistenciais, que também passa a orientar o reordenamento, a oferta e a vinculação de serviços prestados pelas organizações da sociedade civil. É uma importante característica do Suas nessa fase, ainda, a definição de um novo modelo de financiamento baseado no repasse regular e automático fundo a fundo, por meio de um sistema de pisos por proteção, para a garantia de serviços continuados; a adoção de critérios técnicos e de recursos tecnológicos para a partilha de recursos e definição do volume de serviços com base na análise diagnóstica dos territórios; ferramentas e sistemas de planejamento e prestação de contas, entre outros.

A Norma Operacional Básica de Recursos Humanos do Suas - NOB/RH/ Suas (2006) representou um avanço regulatório fundamental para o processo de defesa da desprecarização do setor público. Um dos aspectos mais relevantes da Norma foi a definição de equipes de referência, aprimorada pelas resoluções do CNAS, que delimitaram as atribuições das categorias profissionais de nível superior e dos trabalhadores com formação de nível médio e fundamental no Suas.

$\mathrm{Na}$ esteira da qualificação estatal da política, a Lei do Cebas - Certificado de Entidades Beneficentes de Assistência Social — remeteu às pastas competentes a certificação das entidades beneficentes de assistência social e normatizou a participação das entidades e organizações de assistência social por meio do Vínculo Suas. Essa definição representou um avanço, por deslocar do Conselho Nacional de Assistência Social a responsabilidade da concessão do Cebas, o que fortalece os sistemas públicos de educação e de saúde, ao mesmo tempo em que legitima as organizações da sociedade civil voltadas para o atendimento, o assessoramento e a defesa de direitos na assistência social.

Os avanços no campo normativo-jurídico acompanharam os direcionamentos técnico-políticos, sendo inclusive uma estratégia para garantir maior segurança na transição de governos e estabilidade nos processos de transferência de recursos, sob a fiscalização dos órgãos de controle. A Lei n. 12.435/11 constitui-se, assim, no grande marco legislativo por inscrever o Suas na Loas, assim como as funções e equipamentos de referência essenciais da política. 
A implementação e o aprimoramento do Suas, especialmente no campo normativo/regulatório, têm exigido patamares superiores de estruturação do trabalho e das capacidades institucionais de gestão, com adoção de novos mecanismos e processos direcionados ética e politicamente, o que requer intercâmbio permanente de práticas, de conteúdos ético-políticos relativos às provisões, conformando um campo amplo de conhecimentos plurais na área dos direitos, nos marcos da implantação da educação permanente, qualificando requisições que vão desde o planejamento e diagnóstico socioterritorial até o trabalho social no âmbito dos serviços.

Os trabalhadores do Suas, na aliança com usuários, organizações populares e movimentos sociais, podem, pela natureza da autonomia construída em condições e relações objetivas, fortalecer processos de resistência em defesa do Suas, no contexto atual de fragilização de suas bases. Entretanto, alguns fatores podem dificultar esse protagonismo: frágil inserção de trabalhadores em fóruns e organizações da sociedade civil, especialmente movimentos sociais, com papel de defesa dos direitos; condições e vínculos precários de trabalho; predomínio de uma concepção institucionalista, com centralidades das precrições normativas, e não nos processos que evidenciem projetos de luta pelos direitos, pela dignidade humana.

É importante localizar que essa centralidade na normatização pode estar relacionada à frágil definição da assistência social como direito e a requisição política por sua legitimação na esfera pública do Estado. A construção da esfera pública na assistência social entre 2005 e 2015 demandou um esforço coletivo que priorizou a qualificação política e legal do direito à proteção não contributiva. Movimento indispensável, no espectro dos avanços e lutas emancipatórias políticas, mas insuficiente se não for acompanhado de conteúdo e processo ético-político constitutivo dos projetos coletivos, no sentido da emancipação humana. Ou seja, a dimensão normativa do direito foi fundamental, mas requer mais materialidade e incorporação na agenda política da sociedade civil, das forças sociais, no conjunto das reivindicações e lutas cotidianas da população usuária.

Especialmente a partir da segunda fase do Suas, destaca-se a construção de uma agenda política que produziu centralmente: o aprofundamento do "lugar" da assistência social na proteção social brasileira; o debate e a produção de dispositivos voltados para a desprecarização das condições de trabalho; a construção de parâmetros orientadores dos serviços; o aprimoramento institucional como 
meio para a qualificação das funções da política; a incidência em programas nacionais intersetoriais voltados para a redução da pobreza, e o atendimento de públicos priorizados por políticas transversais, notadamente pessoas com deficiência, infâncias e juventudes, população em situação de rua.

A segunda fase de desenvolvimento e particularidade do Suas inicia-se a partir da aprovação da NOB de 2012, instrumento regulatório que substitui a $\mathrm{Nob} / \mathrm{Suas} / 05$ e agrega o conjunto de instrumentos normativos que detalham a Loas, reformulada com a Lei n. 12.435/11. A Nob/Suas/12 resgata o planejamento como instrumento fundamental de gestão para a qualificação do Suas. Assim, seu desenvolvimento passa a ser impulsionado pela lógica do aprimoramento, considerando responsabilidades, metas e prioridades nacionais a ser detalhadas nos Pactos de Aprimoramento do Suas dos municípios, estados e Distrito Federal, contendo, ainda, a pactuação das responsabilidades da União.

A normativa que regula o funcionamento e as operações de gestão no Suas apresenta inovações importantes em termos da governança democrática, com destaque para: a) fortalecimento dos instrumentos de gestão técnica e financeira, considerando o ciclo de formulação das políticas públicas; b) intensificação da pactuação entre os entes federados, com intensificação do sistema cooperado e compartilhado de responsabilidades/competências; c) definição de prioridades nacionais e metas para a ampliação progressiva da rede de serviços, da sua qualificação; d) incremento de ferramentas e previsões que aperfeiçoam a atuação territorial, como previsão de diagnóstico e indicadores como base para a definição dos níveis de gestão; e) adoção de incentivos financeiros para o aprimoramento de capacidades de gestão; f) fortalecimento da participação e do controle social, assim como das instâncias do Suas.

Além da reafirmação das funções da política (proteção social, vigilância socioassistencial, e defesa de direitos), são detalhados objetivos voltados para a consolidação da gestão compartilhada, com definição de responsabilidades e níveis de gestão, além do respeito à diversidade; do reconhecimento de especificidades, inequidades e desigualdades; do asseguramento de ofertas; da integração da rede com o vínculo Suas; da implementação da gestão do trabalho de educação permanente; da gestão integrada dos serviços e benefícios; da garantia da vigilância e defesa de direitos, tendo em vista sua insuficiente implementação em comparação com a função de proteção social. 
A lógica e a institucionalidade do Suas se mantêm pela organização dos entes por tipos e níveis de gestão (a ser regulados), com substituição da habilitação para adesão. O posicionamento dos entes, considerando responsabilidades e estágios de desenvolvimento, com apurações nacionais e prioridades a ser alcançadas (identificação de demandas territoriais e volume de provisões), possibilita um planejamento com avanços progressivos no ciclo orçamentário, tendo em vista a previsão da formulação do Pacto de Aprimoramento do Suas em consonância com o Plano Plurianual.

As responsabilidades comuns definidas na NOB reafirmam a necessidade de organização do Suas em cada âmbito, a partir de prioridades e metas, com garantia de previsões anteriores, como o comando único, conselho, plano e fundo. Aspectos como infraestrutura para conselhos, estímulo à participação do usuário, publicidade de recursos e implantação de ouvidorias potencializam a governança democrática, assim como a implementação da vigilância, realização de capacitações e implantação da gestão do trabalho, e a previsão de instrumentos de processos de monitoramento e avaliação, expressam a preocupação com a qualificação das capacidades de gestão. O caráter deliberativo dos conselhos é reafirmado nessa normativa, com ênfase nas condições de funcionamento e nas suas responsabilidades no processo de planejamento, normatização e fiscalização.

Outro destaque importante na operacionalização estatal da assistência social no âmbito do Suas é a previsão do modelo compartilhado de cofinanciamento entre os entes, por meio de transferências regulares e automáticas, bem como a necessidade de destinação de recursos para benefícios, serviços, programas e projetos. Os blocos de financiamento são instituídos abrangendo: proteções básica e especial; gestão do Suas; gestão do Programa Bolsa Família e Cadastro Único.

\section{Cristalização da agenda do Suas, sobreposição do Criança Feliz e a via de resistência}

A conjuntura atual requer uma análise das contradições presentes da política de assistência social. As narrativas gerencialistas podem ocultar as implicações de mudanças sutis promovidas no governo Temer. Não é possível o Suas se isolar das contrarreformas drásticas já efetivadas ou em curso (terceirização, trabalhista 
e previdenciária). Os riscos da endogenia operam conformidade ou baixa resistência. Nesse sentido, algumas medidas neoliberais podem ser destacadas e mais bem explicitadas nos seus impactos quanto às bases estruturantes do Suas: aprovação da Lei de Diretrizes Orçamentárias com base no executado de 2016, o que implicou a redução de recursos para 2017; congelamento de recursos pelos próximos vinte anos, com a aprovação do Novo Regime Fiscal (PEC n. 55) e implantação do Programa Criança Feliz, ${ }^{3}$ definido pelo Conselho Nacional de Assistência Social como Primeira Infância no Suas (Resolução n. 20, de 24 de novembro de 2016), sem discussão coletiva e aprofundada nas instâncias do Suas, e aprovação no mês seguinte ao decreto que cria o referido programa.

O Programa Criança Feliz ganhou maior centralidade e difusão nacional, e expressa um risco ao Suas, especialmente pelos seguintes aspectos: contratação de visitadores sociais de forma precarizada, mediante terceirização, com forte tendência de reprodução de conteúdo e práticas conservadores, com efeitos moralizantes da questão social; ausência de novos recursos para sua execução mediante adesão dos municípios e estados, com execução por meio do repasse fundo a fundo pela assistência social, no piso de proteção social básica; problemas de planejamento e alinhamento com demais entes federados; envolvimento de atores que reforçam a cultura tradicional ainda presente na política, especialmente das primeiras-damas que em geral assumem a condução do processo e do comitê de gestão, com evidente constrangimento à autonomia das instâncias do Suas; ingerência de outras políticas e secretarias na execução dos recursos que pertencem à função programática da assistência social, ferindo o comando único; ausência de intersetorialidade entre as políticas no plano nacional; desorganização do processo de implantação com evidente preocupação com o cumprimento de etapas, a exemplo da definição de prazos e processos incoerentes em termos de planejamento (diagnóstico anterior à instalação do comitê gestor); arranjo institucional frágil, que pode trazer dificuldades quanto à fiscalização de órgãos de controle e à qualidade na sua execução; centralidade na primeira infância, desconsiderando outros públicos, vulnerabilidades, situações e ciclos

3. O Programa Criança Feliz foi criado pelo Decreto n. 8.869, em outubro de 2016: “Art. 1. ${ }^{\circ}$ Fica instituído o Programa Criança Feliz, de caráter intersetorial, com a finalidade de promover o desenvolvimento integral das crianças na primeira infância, considerando sua família e seu contexto de vida, em consonância com a Lei n. 13.257, de 8 de março de 2016". 
de vida, ferindo o princípio da universalidade; personalismo na definição de um programa que se sobrepõe ao Suas e pode fragilizar sua continuidade; congelamento das pactuações para expansão qualifica de serviços e recursos, da construção de novos parâmetros de cofinanciamento, com base em custos e especificidades regionais/locais.

As narrativas governamentais podem ser consideradas como armadilhas do gerencialismo, pela ênfase nas justificativas de não expansão com base nas próprias fragilidades do Suas, notadamente a dificuldade dos municípios em executar de forma plena os recursos repassados, por diversas dificuldades inerentes ao pacto federativo nas políticas sociais, como baixa capacidade de gestão e incompreensão da política por atores locais, especialmente os contadores das prefeituras de municípios de pequeno porte. Outro aspecto relevante é a justificativa da impossibilidade de reversão das reformas em curso e do congelamento dos recursos. Sob o argumento fazer mais com menos, a agenda do Suas pode ser ocupada por conteúdos e encaminhamentos gerencialistas, com foco nos resultados, na eficácia.

A cultura burocrática da verticalização pode provocar situações de descontinuidade na oferta de serviços, tendo em vista a centralidade de um programa e a tendência de flexibilização das regras estruturantes de um sistema estatal, além da cultura da implantação pela oferta de recursos federais. As tendências podem levar a uma fragilização do modelo de gestão e das funções da política. Ao mesmo tempo, tem impulsionado resistências, como a não aprovação por conselhos municipais, coletivos de servidores e fóruns populares, bem como organizações de outras políticas.

O direito à proteção social não contributiva com enfrentamento da pobreza, das violações, deve compor as lutas em defesa dos direitos humanos, independente de governos, com incorporação de demandas e grupos invisibilizados, no sentido da construção e ampliação da esfera pública, diante das expressões de desigualdade vivenciadas no cotidiano da maioria dos brasileiros. Entretanto, o cenário atual é de avanço perverso do neoliberalismo, com tendência objetiva de desmonte dos sistemas estatais, ainda que as narrativas apontem o contrário e colaborem para o conformismo. Daí a importância do fortalecimento da assistência social na agenda de lutas por uma seguridade social pública, redistributiva, universal e democrática. 
Os princípios da indivisibilidade e da universalidade dos direitos humanos se aplicam igualmente à proteção social no sentido da construção de uma sociedade de iguais, com justiça social, de espaços e cidades democráticas, justas e mais humanas. A consolidação do Suas, nesse sentido e a partir o II Plano Decenal de Assistência Social (2016/2026), está direcionada para a plena universalização do direito à assistência social, visando alcançar todos que dessa política necessitarem. Volta-se, também, para a plena integralidade da proteção, considerando a presença da assistência social na Seguridade Social brasileira, concebida como ampliada e universal, o que engloba o conjunto de direitos sociais e humanos, bem como as políticas sociais. Universalizar e integralizar é indispensável para enfrentar a desigualdade social histórica, os fenômenos complexos como a violência e a pobreza, o que com certeza deveria ser acompanhada de reformas estruturais efetivamente democráticas, de participação com poder e potencial emancipatório.

O processo de defesa do Suas expressa tensões entre projetos em disputa na esfera pública estatal. É preciso, nesse sentido, reposicionar as bases estruturantes de um direito constitucionalizado nos marcos do Estado democrático de direito e do respectivo sistema estatal, o que supõe financiamento público correspondente às necessidades e volumes de provisões; e práticas deliberativas nas instâncias do Suas, suplantando a burocratização ainda presente nos espaços institucionalizados do Estado.

É no cenário de resistências às reformas, às fragilizações e desmonte dos sistemas estatais, que o II Plano Decenal de Assistência Social se coloca como um instrumento político que expressa o compromisso nacional pela universalização e qualificação da proteção não contributiva, a partir de princípios fundamentais como o da indivisibilidade dos direitos e o da integralidade da proteção social, o que requer consolidar o Suas como modelo de gestão descentralizado e participativo, e avançar na construção de mecanismos potentes para o enfrentamento da desigualdade e da desproteção social.

As medidas adotadas pelo governo ilegítimo de Temer apenas reforçam a subordinação da política social às medidas de austeridade, à política fiscal, num momento de redução e de descontinuidade dos sistemas estatais e das políticas de proteção aos direitos humanos, com evidente redução do Estado e supremacia dos interesses do capital, das corporações. O retrocesso em curso e 
sem precedentes coloca em risco mais que um sistema republicano. O que está em risco são as conquistas sociais engendradas nas lutas por dignidade, bem como as possibilidades institucionais e políticas de defesa dos direitos na via institucional. A reação às contrarreformas e à fragilização do Suas ocultadas pelo gerencialismo disfarçado vem dos agentes políticos inseridos nos espaços coletivos de vocalização e disputa de projetos coletivos, vem da força da sociedade civil, dos movimentos sociais, das lutas populares.

\section{Considerações finais}

Com a implantação e a implementação do Suas, especialmente a partir de 2005, é possível observar importantes avanços normativo-jurídicos, políticos e técnicos, construídos na esfera pública do Estado, a partir de um projeto político popular. Elementos centrais de uma política pública estatal são reconhecidos na nacionalização do direito à assistência social e implantação do modelo descentralizado e participativo de governança democrática. Ao mesmo tempo, identifica-se - em função dos constrangimentos do pacto federativo brasileiro e do histórico de residualidade e meritocracia das políticas sociais, o que contribui para a reprodução da desigualdade - um conjunto de desafios a serem enfrentados, relacionados a fatores como: baixa inserção de sujeitos coletivos com maior potencial de defesa de direitos, engendrada nas lutas sociais na direção emancipatória; fragilidades e inconsistências na descentralização pela baixa capacidade de gestão e a colonialidade do poder nas cidades, com incidência da ideologia conservadora do mando e do favor; insuficiência de recursos pelas operações da desvinculação orçamentária para o pagamento da dívida pública; insuficiente cooperação federativa na composição dos recursos e responsabilidades na provisão de serviços e benefícios socioassistenciais, que correspondam às realidades territoriais; precarização das condições de trabalho e de atendimento; cultura institucional gerencialista e fragmentação entre os direitos e as políticas públicas, entre outros.

Até o golpe conduzido pelo Legislativo, o Judiciário e a mídia, o Suas estava num estágio de aperfeiçoamento institucional e político, de expansão qualificada e mais integrada de serviços e benefícios, com a produção de novos caminhos 
para maior unidade com demais políticas e sistemas. O II Plano Decenal aponta para a revisão de recursos nacionais e compromissos interfederativos, para a plena universalização, desenvolvimento, integração entre serviços e benefícios, gestão democrática e plena integralidade da proteção. Entretanto, as medidas do governo Temer revelam um cenário de redução de direitos, com consequente aumento da pobreza, da fragilização dos vínculos diante da crise moral e frágil respostas substancialmente democráticas do Estado e da sociedade, em especial pela efetivação de serviços com conteúdo ético-político, considerando às necessidades sociais; precarização das condições de vida, com desproteção, desemprego e insegurança social; ampliação da violência e de outros fenômenos multideterminados; aprofundamento da desigualdade nas dimensões socioeconômica, ético-racial e de gênero.

Num cenário de avanço do neoliberalismo, de desmonte dos sistemas estatais, de contrarreformas e perda de direitos conquistados, de subordinação da política social à política fiscal, conduzida na aliança entre oligarquias, capital e corporações, o Suas tem sido minado nas suas bases estruturantes. A cristalização da agenda do Suas, o congelamento de recursos e a implantação do Programa Criança Feliz, no âmbito da arquitetura institucional da política de assistência social, são fatores que abrem caminho para a propagação do conservadorismo aliado ao gerencialismo, bem como dos retrocessos com implicações sociais, políticas e culturais.

Em tempos de aprofundamento da desigualdade e da crise, em suas várias dimensões, com evidente aprofundamento de elementos da sociabilidade do capital como a competição, o individualismo e a fragmentação, de fragilização dos laços sociais, de avanço de ideologias conservadoras ultradireitistas, as políticas públicas, balizadas por concepções meritocráticas e gerencialistas, refuncionalizam a própria sociedade desigual. Daí a importância de dotar as políticas de potencial ético-político emancipatório, pela atuação da sociedade civil, com intensificação e unificação das lutas sociais em defesa da democracia e dos direitos, compreendidos em sua materialidade e função de travessia para uma nova cultura, uma nova sociedade.

Recebido em 24/4/2017 - Aprovado em 12/6/2017 


\section{Referências bibliográficas}

CARBALLIDO, Manuel Eugenio Gándara. Repensando los derechos humanos desde las luchas. Direitos Fundamentais \& Democracia, Curitiba, v. 15, n. 15, p. 41-52, jan.-jun. 2014.

FLORES, J. Herrera. A (re)invenção dos direitos humanos. Trad. Carlos Roberto Diogo Garcia, Antonio Henrique Graciano Suxberger, Jefferson Aparecido Dias. Florianópolis: Fundação Boiteaux, 2009.

LIMA, Cezar Bueno; SILVEIRA, Jucimeri I. Direitos humanos e política social: instrumentos sociojurídicos não punitivos e mecanismos democráticos. Revista de Filosofia Aurora, Curitiba, v. 28, n. 43, p. 147-166, 2016.

NOGUEIRA, Marco Aurélio. Sociedade civil: entre o político-estatal e o universo gerencial. RBCS, Viçosa, v. 18, n. 52, jun. 2003.

WACQUANT, Loïc. As prisões da miséria. Rio de Janeiro: Zahar, 2001. 